\title{
OS LIMITES DA TOLERÂNCIA: UMA ANÁLISE A PARTIR DAS CONCEPÇÕES DE MARCUSE
}

\author{
John Karley de Sousa Aquino ${ }^{1}$
}

\begin{abstract}
Resumo:
O presente artigo tem por objetivo tematizar os limites da tolerância pura, definida por Herbert Marcuse como uma tolerância ilimitada, indefinida, que pressupõe que tudo deve ser tolerado, inclusive o intolerável, como expressões e práticas preconceituosas. Pretendemos a partir do artigo de Marcuse Crítica da tolerância repressiva (1965) delimitar os limites do conceito liberal de tolerância e propor um contra conceito, o de tolerância concreta, com limites definidos que determina a diferença entre o tolerável e o intolerável, desmascarando o caráter ideológico do conceito liberal de tolerância que se tornou repressivo.
\end{abstract}

Palavras-chave: Tolerância pura. Tolerância concreta. Herbert Marcuse.

\section{THE TOLERANCE LIMITS: AN ANALYSIS FROM THE CONCEPTIONS OF MARCUSE}

\begin{abstract}
:
The present paper aims to thematize the limits of pure tolerance, defined by Herbert Marcuse as an unlimited, indefinite tolerance, which presupposes that everything must be tolerated, including intolerable, as biased expressions and practices. We intend from Marcuse's paper Critique of Repressive Tolerance (1965) to delimit the limits of the liberal concept of tolerance and propose a counter concept, that of concrete tolerance, as defined limits that determines the difference between the tolerable and the intolerable, unmasking the liberal concept of tolerance that has become repressive.
\end{abstract}

Palavras-chave: Pure tolerance. Concrecte intolerance. Herbert Marcuse.

\section{Introdução}

Que não venham os despreziveis eunucos nos dizer que são iguais diante de um tribunal da moral um senhor de escravos que, mediante astúcia e violência, acorrenta um escravo, e um escravo que, mediante astúcia e violência, rompe os grilhões!

Trotsky, A moral deles e a nossa

Atualmente nos deparamos com um fenômeno interessante: conservadores com opiniões preconceituosas, que outrora defenderam a censura, reclamando seu direito à liberdade de expressão. Homofóbicos como políticos e pastores da "bancada da bíblia" exigem que suas declarações sejam toleradas em respeito ao direito inalienável que eles têm de emitir suas opiniões sejam elas quais forem. Quando nossos preconceituosos e intolerantes conservadores

\footnotetext{
${ }^{1}$ Doutorando em filosofia pelo programa de pós-graduação em filosofia da UFC. Professor EBTT/IFCE (campus Itapipoca). Vice-líder do grupo de pesquisa Atualidade do pensamento político de Marcuse (UECE) e membro dos grupos de pesquisa Centelha (IFCE) e do Grupo de Estudos marxistas (UFC). E-mail: johnksousa@gmail.com.
} 
recorrem aos ideais modernos de tolerância e liberdade de expressão os limites desses ideais iluministas ficam expostos e é hora de refletirmos sobre isso.

Essa noção de tolerância, de que tudo deve ser tolerado e respeitado é especificamente moderna, faz parte do arcabouço teórico e prático do liberalismo clássico. O conceito de tolerância é, tal como conhecemos hoje, moderno, portanto, burguês e protestante. Surge no contexto de guerras religiosas entre protestantes e católicos na Europa ${ }^{2}$. Naquele período diversos autores entre teólogos, filósofos, juristas, artistas etc., propunham e exigiam a separação entre religião e política, igreja e Estado, demandando a laicidade do Estado e principalmente o respeito à liberdade religiosa entre cristãos, tal reivindicação é o princípio da ideia moderna de tolerância que tem em John Locke, um burguês protestante, em sua famosa Carta sobre tolerância a expressão máxima.

É a essa tolerância que Hanna Arendt recorre em seu polêmico escrito sobre Elizabeth Eckford e os acontecimentos na cidade de Little Rock em 1957. Nos E.U.A. a segregação racial era legalizada em diversos estados do sul e havia escolas exclusivas para brancos e escolas exclusivas para negros. Em 1956 o Supremo Tribunal nos E.U.A. decidiu que a segregação racial nas escolas era ilegal. No entanto em Arkansas as escolas continuavam rejeitando a matrícula de alunos negros, mas em 1957 Elizabeth Eckford e mais oito alunos negros se matricularam em uma escola até então exclusiva para brancos e no dia 04 de setembro de 1957 é a primeira aluna negra a tentar a entrar em uma escola proibida para negros. Ela é vaiada, insultada e agredida por pais de alunos brancos que não aceitam que seus filhos estudem juntos com uma "pessoa de cor". O governador do Estado, declaradamente racista, optou, para evitar conflitos raciais, por fechar por um ano todas as escolas do estado. Após esse episódio Hanna Arendt escreve um artigo intitulado Sobre Little Rock em que reflete sobre o que aconteceu e faz um julgamento de valor sobre o acontecido. Esse artigo de Arendt é um exemplo de liberalismo ao defender explicitamente o direito dos pais brancos de não quererem que seus filhos frequentem a mesma escola que crianças negras, em poucas palavras, como diz Safatle, Hanna Arendt defende o direito dos racistas a "ter uma vida sem negros por perto"3. Para a filósofa Arendt, que se diz solidaria ao movimento dos negros na sua luta por direitos, a intervenção estatal nessa questão é inadmissível, pois viola a liberdade individual dos pais brancos da cidade de Arkansas e, para ela, "forçar os pais a mandar os filhos para uma escola

ABBAGNAMO, 1962, p. 924-925.

3 SAFATLE, O Preconceito é um exercício da liberdade?, in:.http://www.ihu.unisinos.br/78-noticias/572631-opreconceito-e-um-exercicio-da-liberdade

\begin{tabular}{|l|c|c|c|c|}
\hline Qovista Dialectus & Ano 8 & n. 14 & Janeiro - Julho 2019 & p. $110-120$ \\
\hline
\end{tabular}


integrada contra a sua vontade significa privá-los de direitos que claramente lhes pertencem em todas as sociedades livres - o direito privado sobre seus filhos e o direito social à livre associação" " Em poucas palavras: devemos tolerar os pais racistas, pois é um direito individual inalienável ser racista.

Essa mesma problemática reaparece novamente. Diante do que se convencionou chamar "onda conservadora" no Brasil em que presenciamos declarações homofóbicas, racistas, misóginas, xenofóbicas e elogios saudosistas a torturadores dos porões da ditadura em páginas de revistas, no congresso nacional, na TV aberta e nas redes sociais, em que a direita mais reacionária perdeu a vergonha de ser o que é, a saber, preconceituosa e avessa a tudo relativo aos "fracos" como os negros, mulheres, trabalhadores, gays etc, os limites da tolerância devem ser novamente tematizados e questionados. Afinal tudo deve ser tolerado? Temos a obrigação de respeitar todas as opiniões, convicções pessoais e comportamentos? Esses são problemas concretos relativos a um conceito filosófico desenvolvido na modernidade, o conceito de tolerância, conceito esse que propomos tematizar agora a partir das reflexões de Herbert Marcuse.

\section{I.}

Segundo Marcuse se no início da modernidade a tolerância era um valor progressista em contraponto a intolerância religiosa reinante na época, com o estabelecimento do capitalismo e da ascensão da burguesia à condição de classe dominante e principalmente com as experiências nazifascistas do século XX, o ideal liberal de tolerância tornou-se um conceito conservador e às vezes mesmo reacionário, "o que se pratica e proclama hoje como tolerância serve em suas mais eficazes manifestações à causa da opressão"5. Para Marcuse a exigência liberal de que tudo deve ser tolerado é abstrata, pois desconsidera os diversos tipos de opressões e práticas sádicas que são intoleráveis, como declarações e comportamentos racistas, machistas e homofóbicos, pois nem tudo é tolerável. Aliás, o próprio ideal de tolerância dos liberais que principia com Locke é repleto de exceções. Para o autor britânico não seriam toleráveis os que não são cristãos, a vadiagem dos desempregados ou dos mendigos (que para o pai do liberalismo deveriam ser internados em casas de trabalho forçado) e os ateus ${ }^{6}$. É somente com o

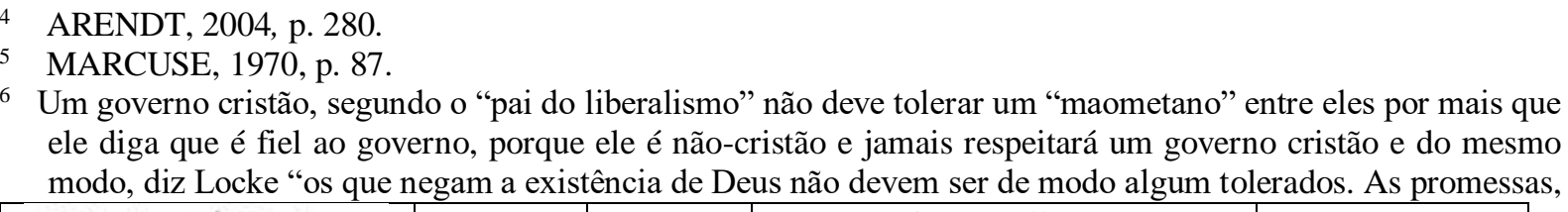

6 Um governo cristão, segundo o "pai do liberalismo" não deve tolerar um "maometano" entre eles por mais que ele diga que é fiel ao governo, porque ele é não-cristão e jamais respeitará um governo cristão e do mesmo modo, diz Locke "os que negam a existência de Deus não devem ser de modo algum tolerados. As promessas,

\begin{tabular}{|c|c|c|c|c|}
\hline Rovista Dialectus & Ano 8 & n. 14 & Janeiro - Julho 2019 & p. $110-120$ \\
\hline
\end{tabular}


desenvolvimento histórico e a constante ascensão da burguesia esclarecida, sobretudo com Voltaire, que os liberais passaram a defender que tudo deveria ser tolerado, inclusive a dominação de classe que agora a burguesia exercia ${ }^{7}$.

Para Marcuse no contexto social e político atual, isto é, do capitalismo tardio, uma sociedade tolerante somente é possível em que a intolerância racista, homofóbica, machista, fascista entre outras for intolerável, "alcança-se a conclusão de que a realização da tolerância exige a intolerância em relação às políticas, atitudes e opiniões predominantes" ${ }^{8}$. O conceito abstrato de tolerância, o de tolerância pura, para o qual tudo deve ser tolerado, tem que ser substituído pelo conceito concreto de tolerância, a saber, que nem tudo deve ser tolerado, pois a intolerância conservadora e preconceituosa é intolerável.

Enquanto o discurso oficial transmite e repete incessantemente mensagens de paz e respeito e sugere que devemos tolerar tudo, os intolerantes seguem agindo impunemente em palavras e ações, sendo tolerados em sua intolerância, assim como as democracias liberais toleraram o nazismo, Francisco Franco, Salazar e Pinochet. Para Marcuse existe uma diferença radical entre a tolerância abstrata, que é uma tolerância repressiva, que tolera o intolerável, e a tolerância concreta, libertadora, que não tolera o intolerável, mas tolera a intolerância dos oprimidos e explorados contra as palavras e atos de opressão e exploração. Segundo Marcuse é dever do intelectual apontar a contradição existente entre o que é dito e o que é feito, entre o discurso oficial e as práticas reais, expondo que,

Não existe hoje poder, autoridade ou governo que traduza a tolerância libertadora na prática, mas acredito constituir tarefa e dever do intelectual recordar e preservar as possibilidades históricas - que constitui sua missão romper a solidez da opressão a fim de abrir o espaço mental em que essa sociedade possa ser reconhecida pelo que é e pelo que faz. ${ }^{9}$

Uma sociedade tolerante em que não existem perseguições por motivos particulares e assuntos privados, como religião e sexualidade, permanece um objetivo não realizado e é a própria burguesia que na modernidade prometeu no lugar da intolerância da nobreza e da igreja a tolerância que impede sua realização ao tolerar a intolerância. A burguesa, mais uma vez, traiu sua própria promessa.

os pactos e os juramentos, que são os vínculos da sociedade humana, para um ateu não podem ter segurança ou santidade, pois a supressão de Deus, finda que apenas em pensamento, dissolve tudo" (LOCKE, 1978, p. 23-24).

7 “As transformações das sociedades democráticas adiantadas, que solaparam as bases do liberalismo econômico e político, alteraram também a função liberal da tolerância” (MARCUSE, 1970, p. 118).

$8 \quad$ MARCUSE, 1970, p. 87.

9 MARCUSE, 1970, p. 87.

\begin{tabular}{|l|c|c|c|c|}
\hline Qovista Dialectus & Ano 8 & n. 14 & Janeiro - Julho 2019 & p. $110-120$ \\
\hline
\end{tabular}


Uma sociedade tolerante em que não exista intolerância pressupõe o fim da intolerância existente e por isso, paradoxalmente, a precondição da tolerância de facto é a intolerância em relação à intolerância, “a eliminação da violência e a redução da opressão na medida necessária a fim de proteger homem e animal da crueldade e agressão são precondições da criação de uma sociedade humanitária"10. A intolerância a intolerância é que gera a verdadeira tolerância. Recorrendo a uma argumentação dialética em que o positivo é resultado da negação da negação, Marcuse afirma que enquanto as condições contrárias ao estabelecimento de uma sociedade tolerante persistir a tolerância permanecerá um objetivo incompleto, pois a tolerância a tudo é que permite a perpetuação da intolerância, "toleram-se políticas, condições e modos de conduta que não deviam ser admitidos porque impedem, se é que não destroem, as oportunidades de criação de uma vida sem medo e sem miséria" ${ }^{11}$. A tolerância com a dominação impede a emancipação, a tolerância com a divisão de classes impede o advento de uma sociedade sem classes, a tolerância com a miséria, com o trabalho infantil, com o racismo, machismo, xenofobia etc., preservam e perpetuam diversas formas de opressões que deveriam ser intoleráveis.

O que Marcuse nos chama atenção é sobre o seguinte problema: por trás do discurso de que devemos respeitar e tolerar tudo, de que por mais que eu não concorde com o que o outro pensa, diz e faz eu teria o dever de respeitar e defender o seu direito de pensar, dizer e fazer ${ }^{12}$, na verdade não estaríamos legitimando e justificando a intolerância reinante? Pior, até que ponto a tolerância pura, abstrata, não é sinônimo de omissão e conformismo?

Marcuse também chama atenção para o fato de que a tolerância defendida pelo status quo na prática é bastante seletiva, pois não se tolera tudo do mesmo modo. Determinadas palavras e ações são menos toleráveis, determinadas minorias e grupos são menos toleráveis que outros. Nos Estados Unidos, de onde Marcuse escrevia e vivia, e na África do Sul, a opressão do racismo branco sobre o negro foi e é diversas vezes tolerada, mas a reação e resposta dos negros contra o racismo institucionalizado ou não dificilmente foram toleradas e na verdade não foi tolerada de modo algum. Na África do Sul os limites da tolerância burguesa na prática foram expostos no massacre de Sharpeville (1960) quando a polícia do governo legalmente racista respondeu com rajadas de metralhadora um protesto pacífico de negros pelo respeito ao direito de ir e vir. Por sua vez a violência do opressor, seja ele racista ou imperialista

MARCUSE, 1970, p. 88.

MARCUSE, 1970, p. 88.

12 Evelyn Beatrice Hall atribui a Voltaire a frase que sintetizaria a liberdade de expressão e a tolerância as diferenças, "Eu desaprovo o que dizeis, mas defenderei até a morte vosso direito de dizê-lo".

\begin{tabular}{|c|c|c|c|c|}
\hline Rovista Dialectus & Ano 8 & n. 14 & Janeiro - Julho 2019 & p. $110-120$ \\
\hline
\end{tabular}


foi e teve que ser tolerada pelos oprimidos, mas não se teve tolerância alguma com a reação dos mesmos: quando os argelinos ou moçambicanos iniciaram suas guerras de libertação, por não tolerarem mais a dominação colonial e racial, os franceses e portugueses responderam com guerras de "pacificação" exigindo tolerância em relação à metrópole. Atualmente a lógica da tolerância seletiva permanece inalterada. O status quo tolera o massacre sionista em Gaza, mas condena a intifada palestina, toleramos o massacre da juventude negra e pobre da periferia e cotidianamente há expressões de intolerâncias com demonstrações públicas de afeto entre pessoas do mesmo sexo, mas consideramos exagero a passeata gay e ações afirmativas em favor das minorias. Na prática a tolerância pura, abstrata, é uma "tolerância repressiva"13. Diz Marcuse,

As autoridades em educação moral e psicologia vociferam contra a delinquência juvenil; vociferam menos, porém, contra a orgulhosa apresentação, em palavras, atos e imagens de foguetes cada vez mais poderosos, mísseis, bombas - a delinquência adulta de toda uma civilização. ${ }^{14}$

I.

Um dos grandes problemas identificados por Marcuse no conceito burguês de tolerância advindo da tradição liberal é que ele é um conceito indeterminado, indefinido. Quando um liberal declara que "tudo deve ser tolerado, devemos respeitar todas as diferenças", põe no mesmo saco o algoz e a vítima, o opressor e o oprimido, sem determinar se devemos tolerar o racismo ou não, por exemplo. Se seguirmos ipso facto a exigência liberal de tolerarmos e respeitarmos tudo indiscriminadamente, seremos obrigados a tolerar o racismo, crimes de guerra, o estupro, a violência doméstica, a pedofilia, assédio moral e sexual, em síntese, todas as formas de opressão e discriminação que nós, que estamos à esquerda no espectro político, somos contra.

A tolerância defendia pelos liberais é abstrata, portanto sem determinação, uma "tolerância pura" que se torna repressiva ao tolerar indiscriminadamente diversas formas de opressão. 'Denomino de tolerância 'abstrata' ou 'pura', diz Marcuse, “essa tolerância nãopartidária na medida em que ela se abstém de tomar partido - mas, ao fazê-lo, ela realmente defende o mecanismo de determinação já estabelecido"15. Tolerar a opressão, a o preconceito e a dominação do forte sobre o fraco é ser partidário da opressão, do preconceito e da dominação

13 MARCUSE, 1970, p. 89.

14 MARCUSE, 1970, p. 89.

15 MARCUSE, 1970, p. 91.

\begin{tabular}{|l|l|l|l|l|} 
Qovista Dialectus & Ano 8 & n. 14 & Janeiro - Julho 2019 & p. $110-120$ \\
\hline
\end{tabular}


do forte sobre o fraco. A neutralidade diante de uma situação de opressão faz de quem se autodeclara neutro um partidário (e por isso um não-neutro) da opressão. Como diz uma frase atribuída a Max Weber, "neutro é quem já se decidiu pelo lado do mais forte”. A tolerância concreta, libertadora, é a tolerância em relação a intolerância do oprimido diante da opressão e a intolerância diante da intolerância do opressor, ou seja, uma tolerância determinada, muito bem definida, que estabelece o que é e o que não é tolerável, "a tolerância que ampliou o escopo e conteúdo da liberdade sempre foi partidária - intolerante para com os protagonistas do status quo repressivo" 16 .

A própria burguesia liberal que levantou contra a aristocracia agrária a bandeira da tolerância, ela mesma não tolerava a aristocracia, o Estado absolutista, a imobilidade social, os privilégios de nascimento, a ausência de liberdade econômica etc. Defendia, portanto uma tolerância concreta, que não tolerava o que no contexto, na gênese da sociedade moderna, era intolerável. As revoluções burguesas, sobretudo a francesa, demonstram, na prática, como era a tolerância da burguesia em ascensão contra a nobreza do antigo regime.

Quando foi que a tolerância burguesa tornou-se tolerância repressiva? Quando a burguesia tornou-se classe dominante e foi capaz de em determinado período satisfazer as exigências gerais enquanto satisfazia seus interesses nos tempos áureos de sua dominação social, política e cultural, no século XIX, no período em que o "capital celebrava suas orgias"17. Segundo Marcuse, “confiante nas eficazes limitações subjacentes impostas pela estrutura de classes, a sociedade parecia praticar a tolerância geral" ${ }^{18}$. Na Inglaterra e nos Estados Unidos bem ou mal as liberdades individuais eram minimamente respeitadas, a oposição podia se expressar e tinha direito de reunião garantido, o que parecia, como diz Marcuse, que a tolerância era uma prática generalizadas nas sociedades liberais do século XIX. Parecia, mas não era. Era, como ainda hoje é, uma tolerância seletiva. Existia uma condição para a burguesia liberal do século XIX tolerar a liberdade de reunião e expressão da classe trabalhadora, era que os trabalhadores não ousassem passar da palavra a ação ${ }^{19}$, "nas sociedades liberais firmemente estabelecidas da Inglaterra e Estados Unidos, a liberdade de expressão e reunião era concedida até mesmo a inimigos radicais da sociedade contanto que não efetuassem a transição da palavra

${ }^{16}$ MARCUSE, 1970, p. 91.

17 MARX, 1983, p. 220.

${ }^{18}$ MARCUSE, 1970, p. 91.

19 "Mesmo quando toleradas dentro dos estreitos limites estabelecidos pela estrutura hierárquica da sociedade, são impotentes enquanto permanecem dentro desses limites" (MARCUSE, 1970, p. 119).

\begin{tabular}{|l|c|c|c|c|}
\hline Q Povista Dialectus & Ano 8 & n. 14 & Janeiro - Julho 2019 & p. $110-120$ \\
\hline
\end{tabular}


ao ato, do discurso a ação" ${ }^{20}$. Kant, um liberal clássico, no seu texto, Resposta à pergunta: $o$ que é o esclarecimento? sintetizou perfeitamente os limites da tolerância das classes dominantes, mesmo as mais liberais e tolerantes, "argumente, tanto quanto quiser e sobre tudo que você gosta, mas obedeça!"21. Quando passou a existir o perigo real da passagem da palavra ao ato as classes dominantes que pregavam a tolerância foram extremamente intolerantes. Os diversos golpes de estado e ditaduras militares no nosso breve século XX demonstram que a burguesia não era tão tolerante com a oposição e com as "diferenças" como ela dizia. O nazifascismo foi a resposta intolerante da burguesia acuada pelo perigo da revolução que não poderia e nem pode ser tolerada.

\section{I.}

No processo sócio-histórico de realização da liberdade existem obstáculos que se mantidos impedem a emancipação, preservando a dominação e as relações de opressão de diversas maneiras. Dessa maneira o sujeito histórico da libertação, a classe dominada, não deve permitir que práticas discriminatórias que reproduzem a opressão sejam preservadas ou existam, assim como as diversas relações de dominação não devem ser toleradas, mas destruídas. Os obstáculos em direção a uma sociedade livre e igualitária não devem ser tolerados, mas retirados do caminho, tudo que impede o progresso em direção à emancipação deve ser desobstruído. Aqueles comprometidos com a tolerância concreta "não pode(m) proteger falsas palavras e falsos atos que contradizem e combatem as possibilidades de libertação" ${ }^{\text {22 }}$. Seria um equívoco um militante negro contra o racismo defender o direito do racista de expressar sua intolerância racial em atos ou mesmo em palavras. Tudo o que contradiz a liberdade e a tolerância concreta é intolerável, pois a tolerância com o intolerável é cumplicidade com a dominação e a opressão, é a tolerância repressiva, o oposto da tolerância libertadora, para tal concepção de tolerância, a concreta, "certas coisas não podem ser ditas, certas ideias não podem ser expressadas, certas políticas não podem ser propostas, certa conduta não pode ser permitida sem transformar a tolerância num instrumento de contínua servidão"23. Todas as manifestações coletivas e individuais de intolerância não devem ser toleradas para que seja possível o estabelecimento de uma sociedade verdadeiramente tolerante. Não é possível

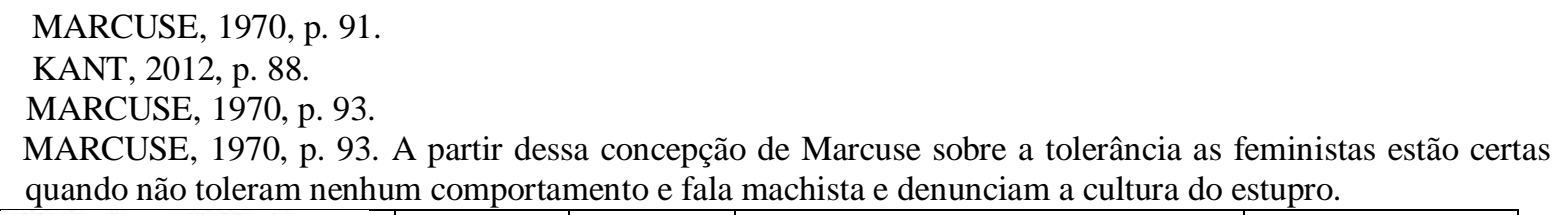

\begin{tabular}{|l|c|c|c|c|}
\hline Rovista Dialectus & Ano 8 & n. 14 & Janeiro - Julho 2019 & p. $110-120$ \\
\hline
\end{tabular}


construir uma sociedade sem machismo quando se tolera o comportamento e declarações machistas que reproduzem continuamente a opressão contra as mulheres.

Em nossa sociedade pragmática, em que a distância entre discurso e ação se encurtou, um discurso intolerante facilmente pode se traduzir em comportamentos intolerantes, principalmente se vindo de figuras públicas que por sua "autoridade" acabam por legitimar as práticas de grupos e indivíduos intolerantes. Devido tal perigo tornou-se necessário a total intolerância com os chamados discurso de ódio que podem e muitas vezes refletem na prática. Os discursos de ódio legitimam as práticas de ódio, de intolerância e opressão ${ }^{24}$ e por isso a proposta de Marcuse de que a esquerda não deve tolerar discursos de ódio, não deve tolerar a intolerância nem mesmo no plano discursivo, pois quando se reprime um discurso xenofóbico podemos evitar perseguições reais aos estrangeiros ${ }^{25}$ e práticas discriminatórias. Diz Marcuse,

No passado e em diferentes circunstâncias, os discursos de líderes fascistas e nazistas constituíram um prólogo de massacres. A distância entre a propaganda e a ação, entre a organização e a sua vazão sobre o povo tornou-se curta demais. Mas a propagação das ideias podia ter sido detida antes de ser demasiado tarde: se a tolerância democrática tivesse sido suspensa quando os futuros líderes se lançaram em campo, a humanidade teria evitado Auschwitz e uma guerra mundial. ${ }^{26}$

Hitler, Mussolini as demais hordas nazifascistas não surgiram do nada, surgiram em reuniões, grupos minoritários, jornais e a partir de propagandas que foram toleradas. Eles foram conquistando um espaço que não deveriam ganhar. Não só a prática fascista, mas o discurso fascista deve ser rechaçado e condenado, isto é, não deve ser tolerado. Não é justificável nenhuma tolerância com discurso e práticas intolerantes. Nem mesmo o recurso liberal ao respeito à liberdade de expressão justifica a tolerância com discursos de ódio.

Uma verdadeira tolerância, libertadora, e não uma tolerância repressiva, como a dos liberais, é aquela que tolera as palavras e ações de grupos que exigem ou simbolizam a

24 No Brasil após o hediondo estupro de uma jovem de 16 anos por 30 homens não faltaram pessoas tentando justificar o crime, responsabilizando a vítima por se expor (sic) a tal situação vexatória, pelo fato dela ser usuária de drogas, por já ser "acostumada" a sair com vários homens e por usar roupas "indevidas". Os discursos de ódio tentam legitimar práticas e comportamentos intoleráveis. O advogado do namorado da vítima, que participou do estupro coletivo declarou, para os jornais que na concepção dele "O conceito jurídico de estupro tem ganhado uma elasticidade nos últimos tempos que eu acho indevida, particularmente" (in:. http://g1.globo.com/rio-de-janeiro/noticia/2016/05/um-dos-suspeitos-do-caso-de-estupro-coletivo-se-entregano-rio.html).

25 No Brasil, em Roraima, na cidade de Mucajaí, manifestante atearam fogo em um abrigo municipal para venezuelanos. A justificativa era que os venezuelanos eram perigosos e estavam trazendo insegurança para as famílias da cidade (In:. https://exame.abril.com.br/brasil/manifestantes-queimam-pertences-de-venezuelanosem-roraima/). Esse crime aconteceu justamente após a proliferação de discursos preconceituosos contra os venezuelanos proferido por figuras públicas da extrema-direita brasileira.

26 MARCUSE, 1970, p. 113.

\begin{tabular}{|l|l|l|l|l|}
\hline Q Povista Qialectus & Ano 8 & n. 14 & Janeiro - Julho 2019 & p. $110-120$ \\
\hline
\end{tabular}


possibilidade de uma civilização não-repressiva e que não tolera os grupos intolerantes, conservadores e reacionários, de modo que a tolerância libertadora que cria as condições para uma sociedade verdadeiramente livre e tolerante pressupõe “(a) intolerância contra os movimentos de direita e tolerância com os movimentos de esquerda" ${ }^{27}$. Em uma sociedade em que a intolerância foi institucionalizada, como no apartheid sul-africano ou as leis de segregação racial nos estados do sul dos E.U.A., seria compactuar com a intolerância oficial tolerar as leis e instituições que legalizam a intolerância. A resposta correta daqueles que lutam pela tolerância concreta e por uma sociedade sem opressões deveria ser a não tolerância em relação a essas leis e instituições intoleráveis. Pregar o respeito e tolerância enquanto na prática o que existe é uma tolerância seletiva e uma intolerância com os fracos é ser conivente com a opressão e as diversas formas de dominação e discriminação.

A tolerância é um ideal, um ideal moderno, iluminista, que ainda estamos para realizar. A nossa realidade não permite que a tolerância seja praticada como ela deveria ser, como se propôs originalmente que devia ser a tolerância: ampla geral e irrestrita. A nossa realidade, racista, machista, homofóbica e intransigente inviabiliza que tudo seja tolerado e mais uma vez “(...) o ideal empalideceu em face da realidade" ${ }^{28}$.

\section{Conclusão}

A intolerância com a opressão e todas as formas de dominação são pré-requisitos para a substituição de uma sociedade desigual e repressiva como a nossa. A "opção pelos pobres" 29 como diz a teologia da libertação tem princípio quando não toleramos mais a miséria material e espiritual, quando não toleramos mais que crianças sejam obrigadas a trabalhar e meninas pobres sejam obrigas a se prostituir, quando não toleramos a violência doméstica que as trabalhadoras estão expostas, quando não toleramos que crianças durmam com fome e que pessoas morram em filas de hospitais, em síntese, quando não toleramos mais a desumanidade da sociedade capitalista. Nesse sentido a concepção liberal de tolerância é inaceitável, "essa espécie de tolerância é desumana" 30 . Se quisermos uma sociedade em que "cada um dar o que pode e recebe o que precisa", em que o machismo, racismo, homofobia e qualquer forma de intolerância não existem ou não são realmente toleradas, então precisamos, diz Marcuse, ser

\footnotetext{
27 MARCUSE, 1970, p. 112.

28 MARX, 1983, p. 220.

29 "Toda a Bíblia, desde o relato de Caim e Abel, está marcada pelo amor de predileção de Deus pelos fracos e maltratados da história humana" GUTIÉRREZ, 1991, p. 309.

30 MARCUSE, 1970, p. 103.
}

\begin{tabular}{|l|c|c|c|c|}
\hline Rovista Q Dialectus & Ano 8 & n. 14 & Janeiro - Julho 2019 & p. $110-120$ \\
\hline
\end{tabular}


“intolerantes, militantemente intolerantes e desobedientes às normas de condutas que tolera a destruição e a repressão" 31 . Toda solidariedade aos professores perseguidos pelo projeto fascista "Escola sem partido" e "nenhuma liberdade aos inimigos da liberdade" 32.

\section{Referências:}

ABBAGNAMO, Nicola. Dicionário de Filosofia. Tradução de Alfredo Bosi com a colaboração de Maurice Cunio et al. $2^{\circ}$ Edição. São Paulo: Mestre Jou, 1962.

ARENDT, Hanna. Sobre Little Rock. In: Responsabilidade e julgamento: escritos morais e éticos. Tradução de Rosaura Eichemberg. São Paulo: Companhia das letras, 2004.

GUTIERREZ, Gustavo. Pobres y opción fundamental. In: I. Ellacuría; J. Sobrino (eds.) Mysterium liberationis: conceptos fundamentales de la teología de la liberación. San Salvador: UCA, tomo I, 1991.

KANT, Immanuel. Resposta à pergunta $\mathrm{O}$ que é o iluminismo? Tradução de Claúdio J.A. Rodrigues. In: Filosofia da história: Textos extraídos das obras completas de Kant. $1^{\circ}$ Edição. São Paulo: Ícone, 2012.

LOCKE, John. Carta acerca da tolerância. In: : Coleção Os pensadores. Tradução de Anoar Aiex e E. Jacy Monteiro. $2^{\circ}$ Edição. São Paulo: Abril Cultural, 1978.

MARCUSE, Herbert. Crítica da tolerância repressiva. In: Crítica da tolerância pura. Tradução de Ruy Jungmann. Rio de Janeiro: Zahar Editores, 1970.

MARX, Karl. O Capital: Crítica da economia política. Tradução de Regis Barbosa e Flávio R. Kothe. São Paulo: Abril Cultura, 1983.

MARCUSE, 1970, p. 126.

32 Saint Just no seu discurso em favor à condenação à morte do Rei Luís XVI.

\begin{tabular}{|c|c|c|c|c|}
\cline { 2 - 4 } Q Oenista & Ano 8 & n. 14 & Janeiro - Julho 2019 & p. $110-120$ \\
\hline
\end{tabular}

